\title{
Monitoramento do NDVI da Urochloa brizantha cv. Marandu em função das doses de nitrogênio com uso de câmera multiespectral
}

\section{Monitoring the NDVI of Urochloa brizantha cv. Marandu as a function of nitrogen doses with multispectral camera use}

\author{
João Lucas Aires Dias (D) ${ }^{1}$, Izaías de Macedo Barros (D) ${ }^{1}$, Paulo Alexandre Rodrigues Pereira (D) ${ }^{1}$, Pedro Matheus Barboza \\ Barros (D) ${ }^{2}$, Sabino Pereira da Silva Neto (D) $^{3}$ \\ ${ }^{1}$ Universidade Federal do Tocantins (UFT), Gurupi, TO, Brasil \\ 2 Universidade Federal de Viçosa (UFV), Viçosa, MG, Brasil \\ ${ }^{3}$ Instituto Federal de Ciência e Tecnologia do Tocantins (IFTO), Gurupi, TO, Brazil
}

\section{Resumo}

Objetivou-se avaliar o índice vegetativo da diferença normalizada (NDVI) do dossel da Urochloa brizantha cv. Marandu em função das doses de nitrogênio, com o uso de câmera multiespectral e sensor óptico ativo. Além disso, realizou-se estudo de correlação entre o NDVI, obtido pela câmera e o sensor óptico, e as características produtivas do capim Marandu. Os tratamentos foram compostos por cinco doses de nitrogênio (N) correspondentes a $0 ; 62,50 ; 125 ; 187 ; 40$; e $250 \mathrm{mg} \mathrm{dm}^{-3}$. Antes da semeadura, aplicou-se $2250 \mathrm{mg} \mathrm{dm}^{-3}$ de calcário dolomítico. Foram aplicados $200 \mathrm{mg} \mathrm{dm}^{-3}$ de fósforo $\left(\mathrm{P}_{2} \mathrm{O}_{5}\right)$ no plantio e $300 \mathrm{mg} \mathrm{dm}^{-3}$ de potássio $\left(\mathrm{K}_{2} \mathrm{O}\right)$. As predicações das equações de regressão indicam que as respostas espectrais do dossel da planta forrageira foram influenciadas pela aplicação de N. Em todas as situações os valores de NDVI adquiridos pelo sensor óptico ativo se ajustaram a modelos matemáticos de regressão de segundo grau, e os da câmera multiespectral, apenas aos 42 dias de crescimento após a adubação, ajustaram-se ao modelo linear. Assim, a câmera digital convertida e o sensor óptico ativo detectaram mudanças na reflectância espectral do dossel da cultivar Marandu em reposta à adubação nitrogenada.

Palavras-chave: Gestão. Luz. NDVI. Pecuária de precisão.

\begin{abstract}
The objective of this study was to evaluate the normalized difference vegetative index (NDVI) of the canopy of Urochloa brizantha $\mathrm{cv}$. Marandu as a function of nitrogen
\end{abstract}


doses, using a multispectral camera and active optical sensor. In addition, a correlation study was conducted between the NDVI obtained by the camera and the optical sensor and the productive characteristics of Marandu grass. The treatments consisted of five nitrogen doses $(N)$ corresponding to $0,62.50,125,187.40$ and $250 \mathrm{mg} \mathrm{dm}^{-3}$. First, $2250 \mathrm{mg} \mathrm{dm}^{-3}$ of dolomitic limestone was applied prior to sowing, while $200 \mathrm{mg} \mathrm{dm}-3$ phosphorus $\left(\mathrm{P}_{2} \mathrm{O}_{5}\right)$ and $300 \mathrm{mg} \mathrm{dm}^{-3}$ potassium $\left(\mathrm{K}_{2} \mathrm{O}\right)$ were applied at planting. The predictions of the regression equations indicate that the forage plant canopy spectral responses were influenced by the $N$ application. The NDVI values acquired by the active optical sensor fit the second degree mathematical regression models and those of the camera in all situations, and multispectral growth adjusted to the linear model only at 42 days after fertilization. Thus, the converted digital camera and the active optical sensor detected changes in the spectral reflectance of the Marandu cultivar canopy in response to the nitrogen fertilization.

Keywords: Management. Light. NDVI. Precision livestock.

\section{Introdução}

0 rebanho bovino brasileiro possui 218,23 milhões de cabeças, que são mantidas, principalmente, em regime de pastejo (IBGE, 2016), das quais quase $90 \%$ estão em solos ácidos e de baixa fertilidade. Diante disso, a necessidade de fertilização de pastagens é evidente, tendo em vista que a grande maioria dos solos não fornece nutrientes de maneira adequada para o crescimento das plantas e nos níveis de extração das gramíneas utilizadas na formação de pastagens cultivadas (Martha Jr. et al., 2007).

A sustentabilidade da pecuária em termos agronômicos, econômicos e ambientais tem como principal obstáculo o declínio na produtividade das pastagens, principalmente devido à ausência de cuidados com a fertilidade do solo. Dentre os diversos nutrientes necessarios à planta, a adubação nitrogenada tem papel importante, tendo em vista que essa atua positivamente sobre os fatores morfológicos da gramínea forrageira, estimulando seu crescimento e, consequentemente, concorrendo para o aumento da produtividade da pastagem (Martha Jr. et al., 2007).

A avaliação do status nutricional, relacionado ao nitrogênio (N) em gramíneas e diversas culturas, tradicionalmente envolve métodos caros, demorados e potencialmente poluidores do meio ambiente. Entretanto deteç̧ões automáticas têm sido desenvolvidas de forma eficaz e prática, sendo menos onerosas e podendo ser relacionadas com outras variáveis tais como a biomassa disponível e a cobertura do solo. Além disso, esses sistemas podem se correlacionar no espaço e tempo, bem como a biomassa de forragem disponível e o comportamento dos animais em pastejo (Roberts et al., 2010).

No mercado existem medidores portáteis de clorofila, com contato físico com as folhas, que correlacionam as propriedades espectrais de transmitância de energia eletromagnética das lâminas foliares e o teor de $\mathrm{N}$ na planta (Dworak et al., 2013). Além desses, o sensoriamento remoto tem se mostrado eficaz para a avaliação do status nutricional e produtividade das pastagens, por meio, principalmente, dos índices de vegetação (Abrahão et al., 2009).

Entre essas medidas de refletância do dossel forrageiro, as comumente usadas para avaliar o status nutricional das plantas, da biomassa e a concentração de nutrientes são os índices vegetativos da diferença normalizada baseados nas refletâncias do vermelho (NDVI) e verde (GNDVI) (Silva Jr et al., 2008).

As medidas de NDVI podem ser tomadas com o uso de câmeras que utilizam dois ou mais chips, os quais operam em diferentes comprimentos de ondas que posteriormente permitem calcular o referido índice. Essas câmeras, no entanto, possuem designer óptico complexo, o que eleva o seu valor de aquisição. Portanto o interesse por projetos que utilizem câmeras convencionais de chip único, que operem com filtro óptico multiespectral, vem aumentando em razão dos baixos custos de sua conversão.

Dessa forma, objetiva-se com essa pesquisa avaliar o índice vegetativo da diferença normalizada (NDVI) do dossel da Urochloa brizantha cv. Marandu em função das doses de nitrogênio, com o uso da câmera multiespectral. 


\section{Material e métodos}

0 experimento foi implantado entre os meses de dezembro de 2014 e abril de 2015, em condições de casa de vegetação no Instituto Federal do Tocantins, Campus Gurupi, onde a gramínea Urochloa brizantha cv Marandu foi cultivada em vasos plásticos sem furos, com capacidade de 8 litros, contendo como substrato 5 litros de areia e 2,5 litros de vermiculita, totalizando o volume de 7,5 litros, na proporção de $2: 1 \mathrm{v} \mathrm{v}^{1}$. Foram realizados desbastes periódicos de plantas até que permanecessem cinco plantas vaso${ }^{1}$. A cada três dias realizou-se o remanejamento das posições dos vasos nas bancadas, para que todas as plantas tivessem a mesma condição de clima e temperatura em diferentes lugares da casa de vegetação.

0 delineamento experimental utilizado foi inteiramente casualizado em esquema fatorial, com parcela subdividida no tempo, com cinco tratamentos e cinco repetições. Os tratamentos foram compostos por cinco parcelas de doses de nitrogênio (ureia) correspondentes a $0 ; 62,50$; 125; 187,40; e $250 \mathrm{mg} \mathrm{dm}^{-3}$, sendo que para cada tratamento tinha cinco repetições, compondo vinte e cinco vasos por tratamento e as subparcelas pelos cinco diferentes períodos de cortes 14, 21, 28, 35 e 42 dias, formando um total de 125 vasos.

A contagem das idades começou após 30 dias de emergência das plantas, quando se realizou o corte de uniformização a $10 \mathrm{~cm}$ de altura do solo. Independente do tratamento, realizou-se a adubação em dose única de $200 \mathrm{mg} \mathrm{dm}^{-3}$ de fósforo (super fosfato simples) no plantio, juntamente com a primeira dose de nitrogênio de cada tratamento, e uma semana após a semeadura com $300 \mathrm{mg} \mathrm{dm}^{-3} \mathrm{de}$ potássio (cloreto de potássio) mais $2250 \mathrm{mg} \mathrm{dm}^{-3} \mathrm{de}$ calcário (calcário dolomítico).

Os efeitos das doses de nitrogênio nas características agronômicas da gramínea foram estudados durante os cinco períodos de tempo. Em cada período foram realizadas coletas da altura, NDVI e de amostras das plantas com cortes a $10 \mathrm{~cm}$ acima do solo para determinação da produção da matéria seca dos tratamentos, pesando-se a lâmina foliar, colmo e material morto e levando-os para a estufa de circulação forçada de ar, à temperatura de $65^{\circ} \mathrm{C}$, até atingirem peso constante.
Para analisar a refletância espectral do dossel forrageiro foi empregado o índice de vegetação por diferença normalizada (NDVI), utilizandose sensor óptico ativo, o qual serviu como parâmetro para validar os resultados da câmera multiespectral. O sensor óptico possui dois LED's, que emitiam radiação ativa em dois comprimentos de onda centralizada no vermelho $(660 \mathrm{~nm})$ e no infravermelho próximo $(770 \mathrm{~nm})$, com largura espectral de $25 \mathrm{~nm}$. Já a câmera multiespectral foi convertida por meio da remoção do filtro de vidro que bloqueia a passagem do comprimento de onda do infravermelho e, em seu lugar, inseriu-se um filtro multiespectral que permite a passagem dos comprimentos de ondas do vermelho e infravermelho próximo.

As leituras do NDVI foram realizadas pelo sensor óptico ativo GreenSeeker ${ }^{\circledR}$ modelo HCS-100 e com a câmera convencional Canon PowerShot A495 de chip único. Os dados de ambos foram coletados a $60 \mathrm{~cm}$ de altura do topo do dossel da gramínea. As imagens dos dosséis da gramínea foram processadas e convertidas em imagens que informam o NDVI. Para isto, utilizou-se o programa ImageJ. Já os valores de NDVI coletados pelo sensor óptico ativo foram calculados internamente por meio da seguinte equação:

$$
\mathrm{NDVI}=\frac{\mathrm{NIR}-\mathrm{RED}}{\mathrm{NIR}+\mathrm{RED}}
$$

NIR é a reflectância no infravermelho próximo e RED é a reflectância no vermelho. O NDVI pode variar de $-1 \mathrm{a}+1$. Valores negativos representam solo nu ou sem vegetação, e os valores maiores que zero representam a vegetação.

Após as coletas periódicas, os dados foram submetidos à análise de variância e regressão para verificar a significância do efeito das doses de N sobre os atributos avaliados, utilizando-se o programa Assistat versão 7.5 beta. A escolha da equação de regressão foi realizada com base no coeficiente de determinação $\left(\mathrm{R}^{2}\right)$, na significância da regressão e de seus coeficientes, testados ao nível de $1 \%$ e $5 \%$ de probabilidade. Os dados das características agronômicas da gramínea se submeteram a estudo de correlação com os valores de NDVI da câmera digital e do medidor portátil. 


\section{Resultados e discussão}

As predições das equações de regressão indicam que as respostas espectrais do dossel da planta forrageira foram influenciadas pela aplicação de N. Em todas as situações com o sensor óptico, os valores do NDVI se ajustaram a modelos matemáticos de polinomial. Já com a câmera multiespectral, apenas aos 42 dias de crescimento após a adubação os valores de NDVI se ajustaram ao modelo linear.

As regressões com a avaliação do sensor óptico ativo e da câmera multiespectral também apresentaram altos valores de coeficientes de determinação. Assim, as estimativas são adequadas para caracterizar as alterações da reflectância espectral provocadas pelas doses de $\mathrm{N}$ aplicadas ao capim Marandu. A resposta quadrática se deve em parte ao aumento da clorofila, que ao atingir o ponto de maturidade fotossintética se estabiliza em determinado patamar e, assim, mantémse invariável mesmo após o incremento de $\mathrm{N}$ no tecido vegetal (Costa et al., 2001). Na Figura 1 são apresentadas as predições das respostas espectrais da gramínea com uso de sensor óptico ativo.

Os maiores valores de NDVI foram encontrados com adubação teórica de 166,67; 150; 200; 214,30; $333,34 \mathrm{mg} \mathrm{dm}^{-3}$ aos $14,21,28,35$ e 42 dias de crescimento após a adubação com nitrogênio com os respectivos NDVIs: 0,$24 ; 0,3 ; 0,27 ; 0,39$; e 0,38 . Isso significa que qualquer quantidade de $\mathrm{N}$ acima desses valores provocará uma redução no NDVI quando colocada nas plantas. Já na Figura 2 são apresentadas as predições, por meio de regressões, das respostas espectrais da gramínea com o uso da câmera digital.

Na câmera multiespectral, os maiores valores de NDVI foram encontrados com adubação teórica de 150; 162,5; 225; e $200 \mathrm{mg} \mathrm{dm}^{-3}$ aos 14, 21, 28 e 35 dias de crescimento após a adubação com N, sendo esses valores 0,$11 ; 0,13 ; 0,13$; e 0,18 . Ou seja, qualquer quantidade de $\mathrm{N}$ acima desses valores provocará uma redução no NDVI. Apenas aos 42 dias de idade nota-se um modelo linear crescente do valor de adubação, observando que o gráfico apresenta intenção para regressão quadrática. Estima-se que se fosse dada continuidade à pesquisa aumentando as doses de $\mathrm{N}$, também se adequaria a equação de segundo grau.
A análise dos gráficos demonstra que aos 28 dias de idade é o período ideial para monitoramento da adubação nitrogenada, já que aos 35 dias se encontra o maior valor de NDVI; ou seja, em condição de campo, se a área de pastagem necessita de ajustes, esse seria o tempo apropriado para chegar aos 35 dias de idade em boa condição de pastejo.

0 principal componente morfológico consumido pelos animais em pastejo são as folhas. Assim, os técnicos de campo realizam o ajuste da taxa de lotação animal considerando, principalmente, a disponibilidade de lâminas foliares, ajustando os valores da câmera multiespectral e do sensor ao modelo matemático de regressão linear do NDVI com as características agronômicas do capim Marandu, onde nota-se correlação positiva em todas as idades de crescimento das plantas.

Nas Figuras 3 e 4 são apresentados os coeficientes de correlação do NDVI do sensor óptico e da câmera multiespectral e as respostas produtivas da Urocholoa brizantha cv. Marandu.

Observa-se que entre as idades de 21 e 35 dias, a câmera (Figura 4) detectou maiores valores de coeficiente de correlação de Pearson $\left(r^{2}\right)$ e o sensor (Figura 3) aos 35 dias de idade. Já os dois equipamentos, aos 14 dias de idade, apresentaram os menores valores de $\mathrm{r}^{2}$, a qual foi a idade de menor dose de $\mathrm{N}$ aplicada. Com relação às características produtivas, tanto a câmera como o sensor mostraram maior relação com a matéria seca das lâminas foliares (MSFL), e os menores valores foram obtidos em matéria seca de material morto (MSMM).

Esses resultados eram esperados, uma vez que as folhas senescidas se encontram na base da planta, as quais têm seus nutrientes translocados, diminuindo, assim, sua reflectância. Dessa forma, confirma-se que o uso da câmera multiespectral e do sensor óptico ativo podem ser viáveis no monitoramento da reflectância espectral do Marandu.

Essas alterações na reflectância são provocadas principalmente pela quantidade de clorofila na planta, que por sua vez é alterada em função do $\mathrm{N}$ disponível no tecido vegetal, pois quando se aplica uma quantidade elevada de $\mathrm{N}$ na planta, há um aumento na clorofila e, com isso, a absorção da radiação na região do visível é maior, causando o aumento do NDVI (Read et al., 2003). 
14 dias

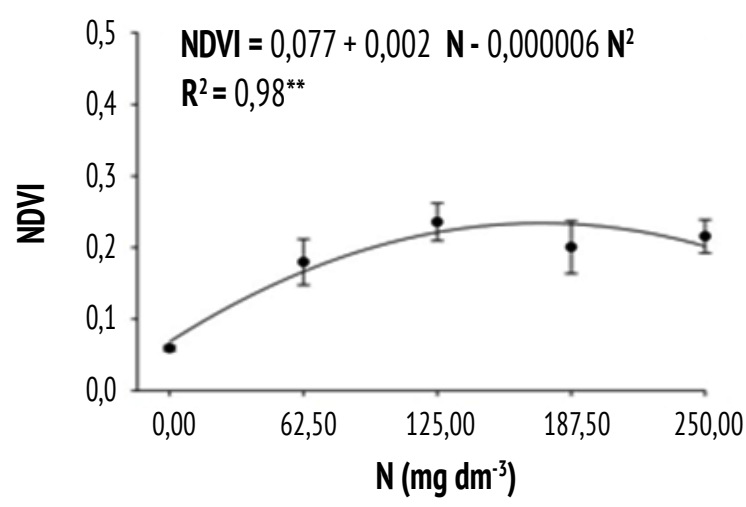

28 dias

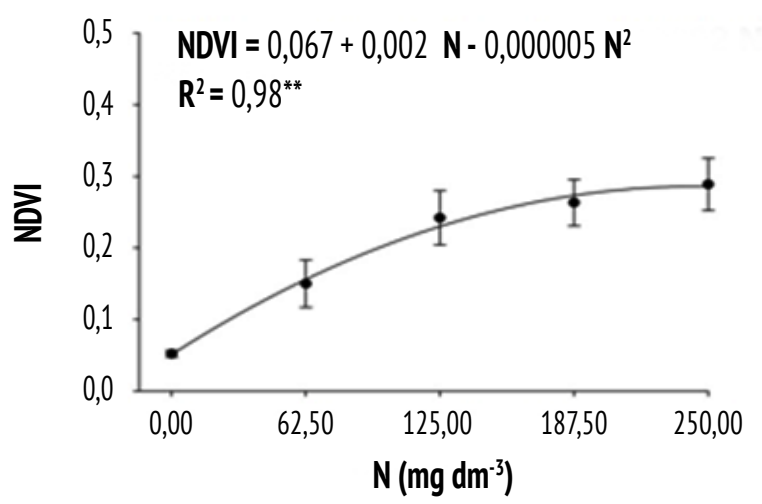

21 dias

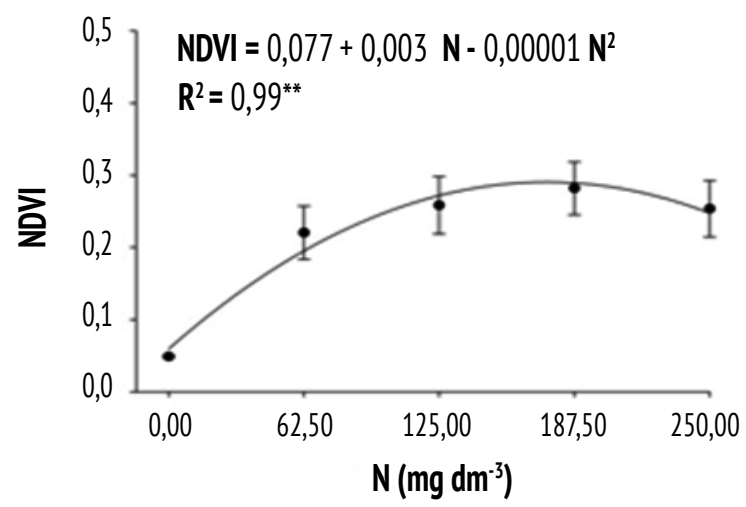

35 dias

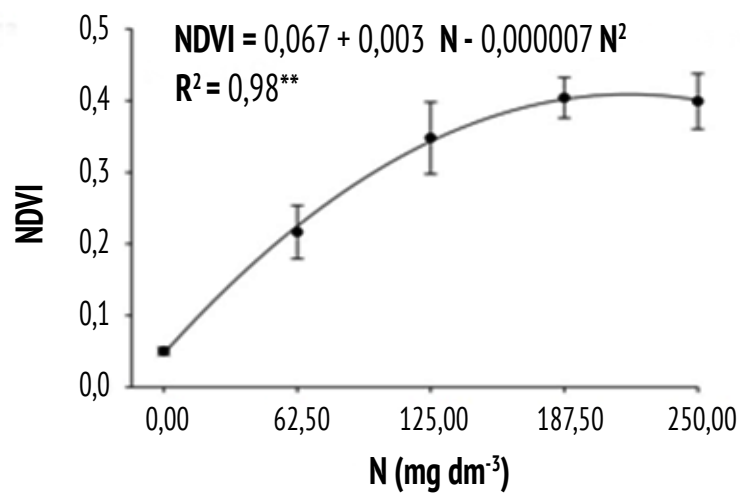

\section{2 dias}

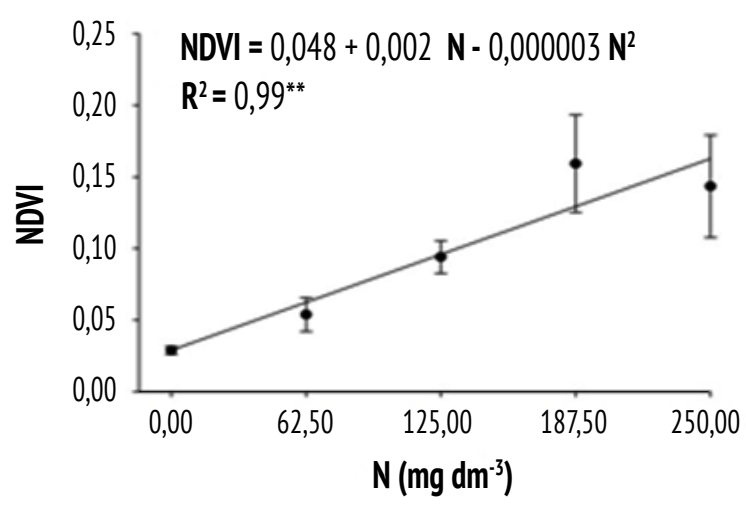

Figura 1 - Índice Vegetativo da Diferença Normalizada (NDVI) com o sensor óptico da Urochloa brizantha cv. Marandu em função de doses de nitrogênio (N) aos 14, 21, 28, 35 e 42 dias após corte de estabelecimento e da adubação. ** Regressão significativa ao nível de $1 \%$ de probabilidade. Fonte: dados produzidos pelos autores (2015). 
14 dias

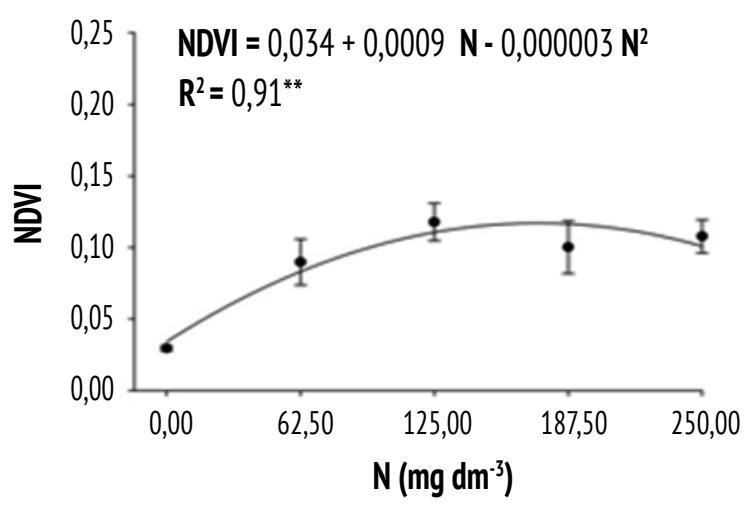

28 dias

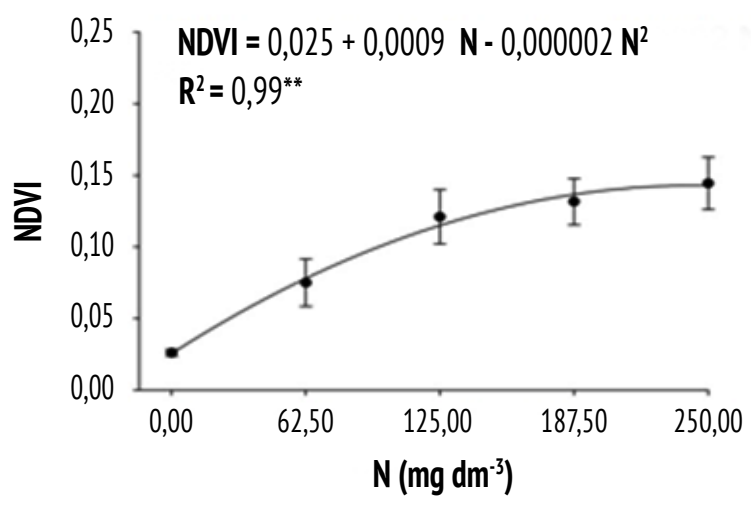

21 dias

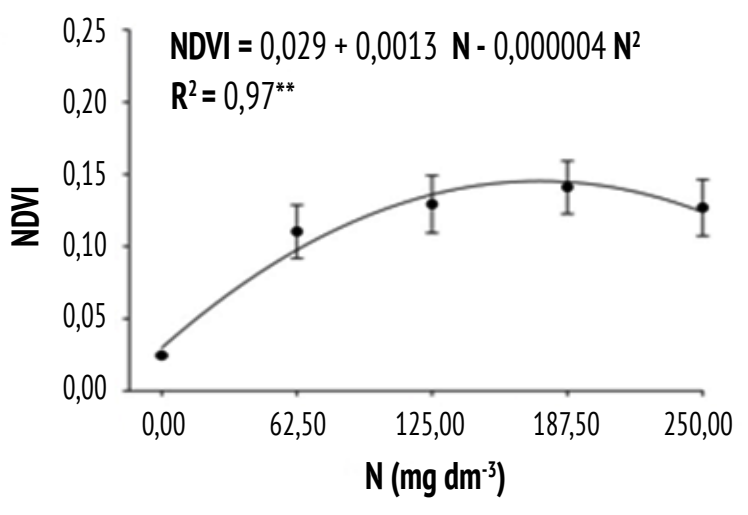

35 dias

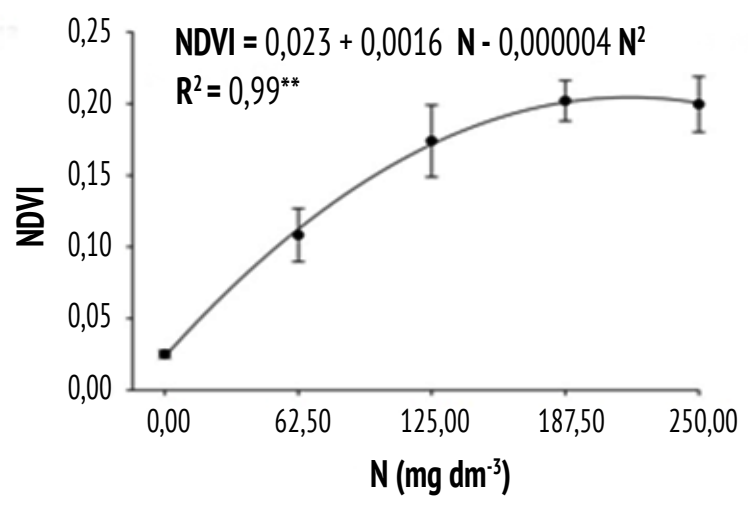

42 dias

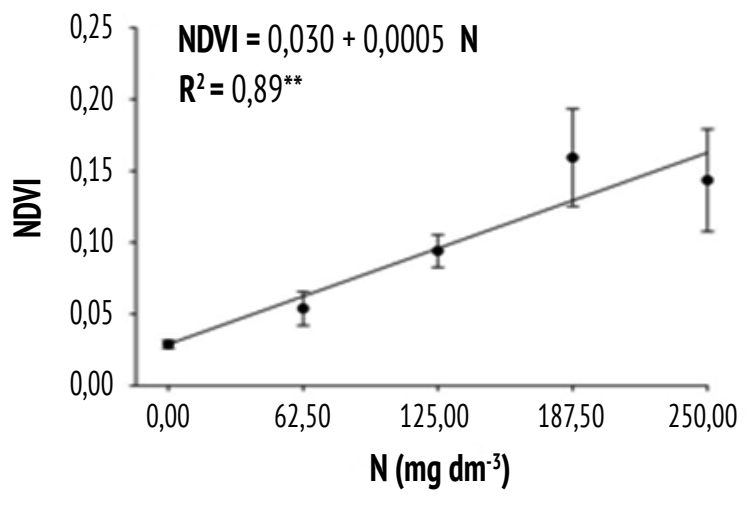

Figura 2 - Índice Vegetativo da Diferença Normalizada (NDVI) com o sensor óptico da Urochloa brizantha cv. Marandu em função de doses de nitrogênio (N) aos 14, 21, 28, 35 e 42 dias após corte de estabelecimento e da adubação. ${ }^{* *}$ Regressão significativa ao nível de $1 \%$ de probabilidade. Fonte: dados produzidos pelos autores (2015). 
Altura x NDVI

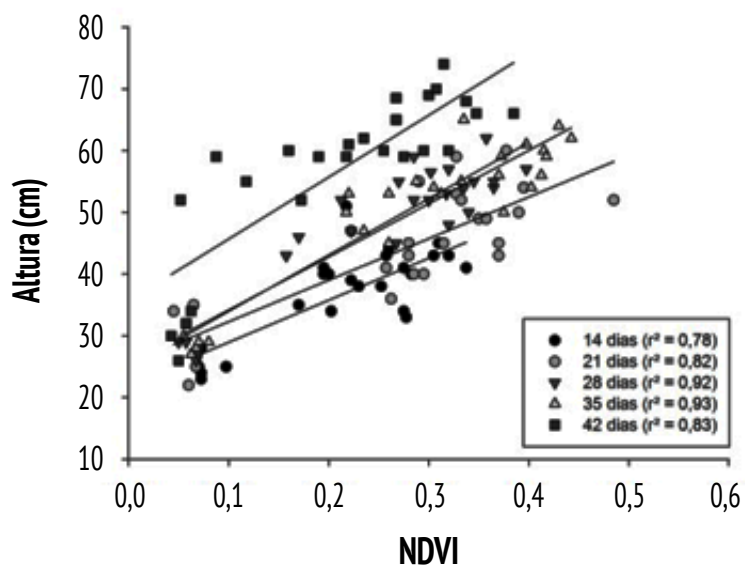

MSCM x NDVI

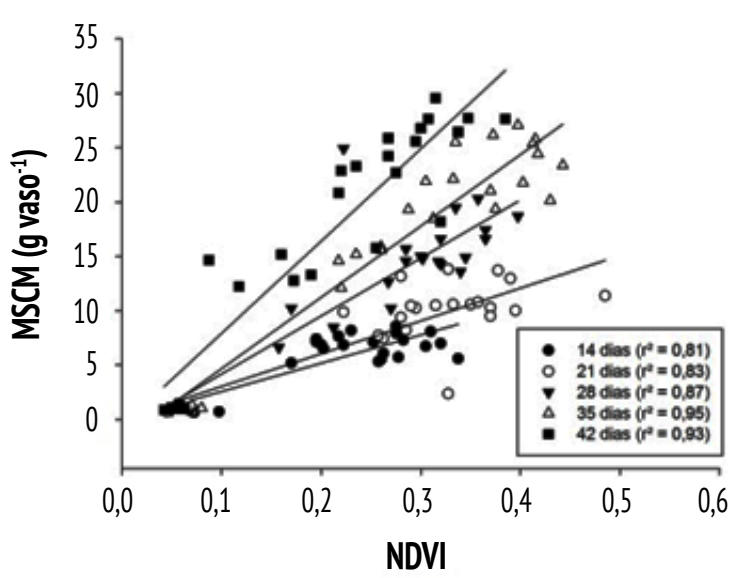

MSLF x NDVI

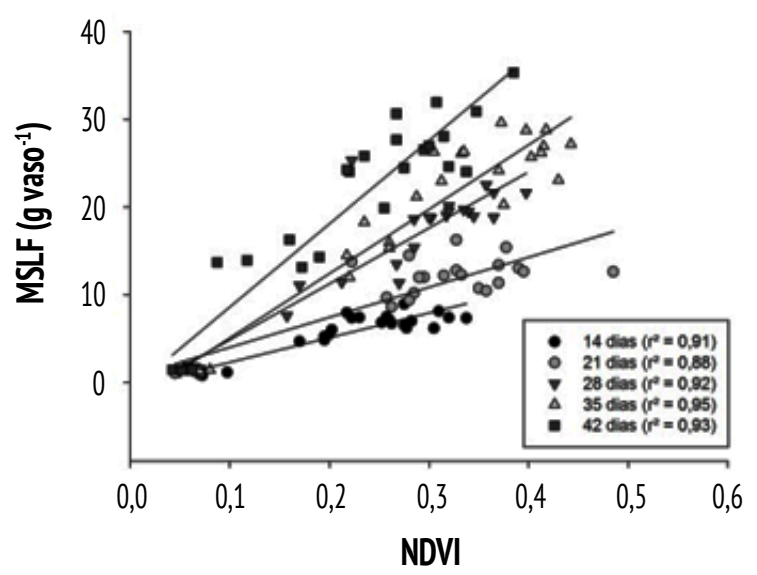

MSMM x NDVI

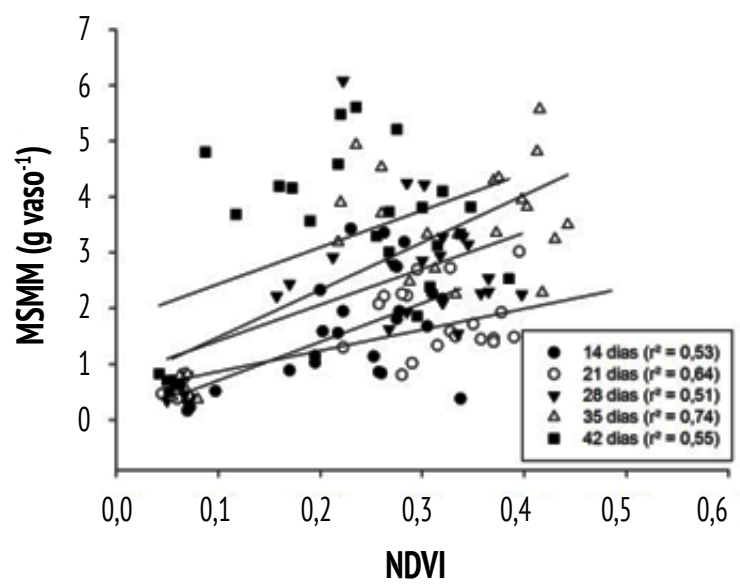

Figura 3 - Coeficiente de correlação entre 0 índice vegetativo da diferença normalizada (NDVI) do sensor óptico e as respostas produtivas da Urochloa brizantha cv. Marandu, matéria seca da lamina foliar (MSLF), colmo (MSCM) e materil morto (MSMM) aos 14, 21, 28, 35 e 42 dias de crescimento após adubação. Fonte: dados produzidos pelo autor (2015). 


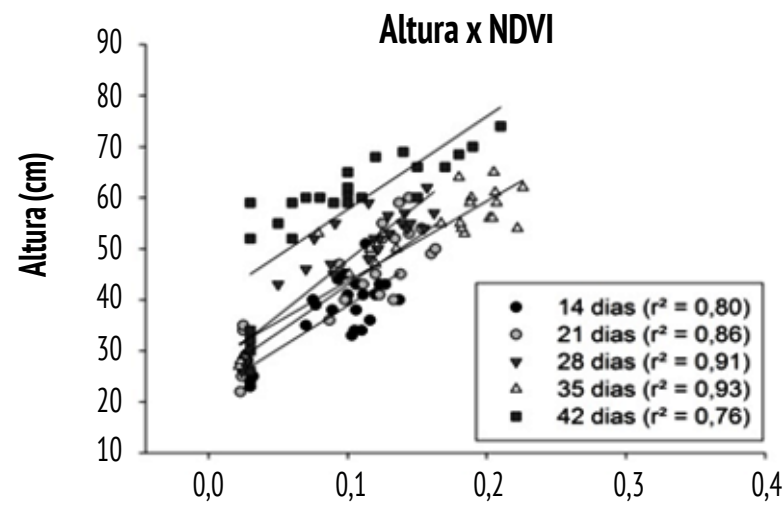

NDVI

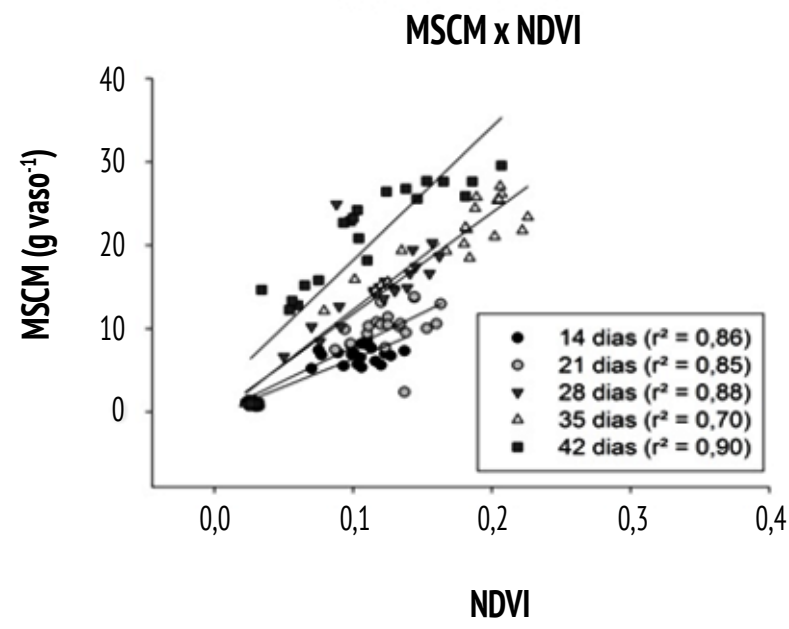

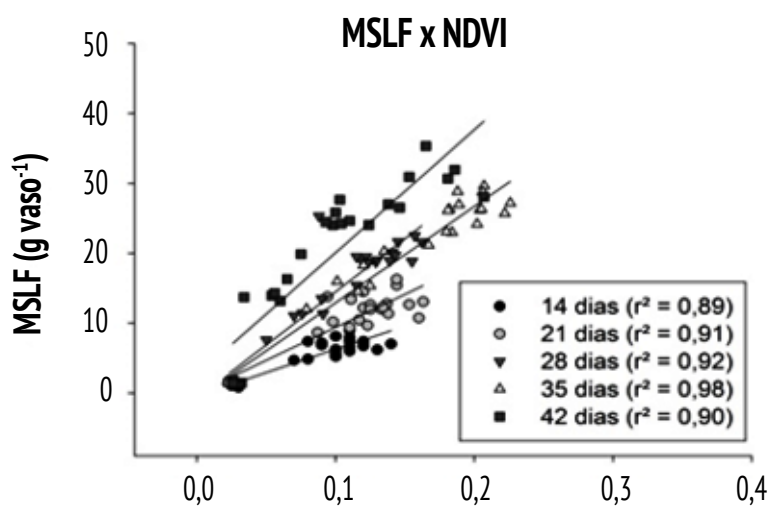

NDVI

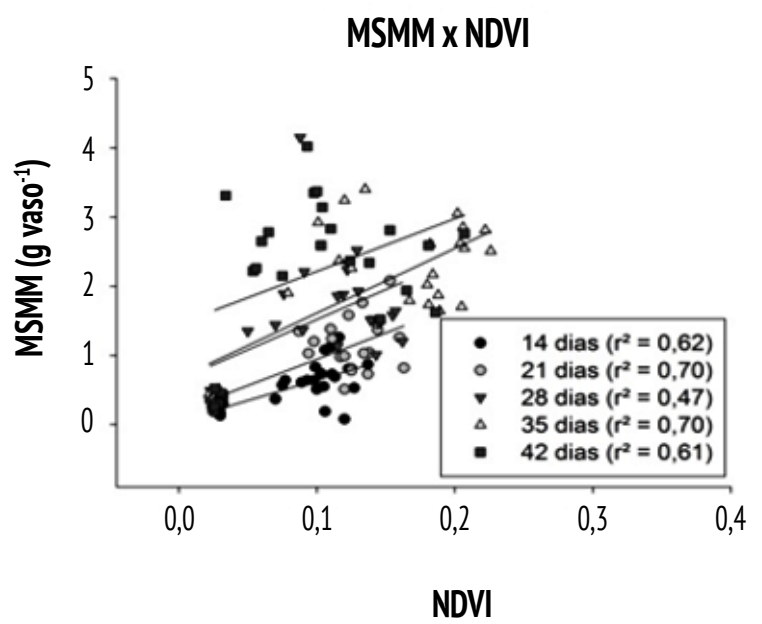

Figura 4 - Coeficiente de correlação entre o índice vegetativo da diferença normalizada (NDVI) da câmera multiespectral e as respostas produtivas da Urochloa brizantha cv. Marandu, matéria seca da lamina foliar (MSLF), colmo (MSCM) e materil morto (MSMM) aos 14, 21, 28, 35 e 42 dias de crescimento após adubação. Fonte: dados produzidos pelo autor (2015).

Nota-se que os aparelhos apresentam valores de NDVI diferentes de um equipamento para o outro, sendo uma possível causa a diferença da área capturada do sensor óptico ativo em formato elíptico e a área da imagem capturada pela câmera em formato rentangular. Com isso, a câmera apresenta vantagem, pois o sensor óptico analisa pontos específicos, sendo necessario tabular dados para então gerar o mapeamento da área de pastagem. Já a câmera, quando aclopada em veículos não tribulados, pode capturar imagens e gerar mapas que permitem identificar, com maior agilidade, locais com características específicas da produtividade da gramínea, sendo um potencial para aplicações práticas na pecuária, como ajuste de taxa de lotação animal, desse modo usando a matéria seca de lâmina foliar, e também para indicadores de deficiência de N. Desta forma, pode auxiliar os produtores rurais na tomada de decisões quanto ao manejo da pastagem e à conservação do solo. 


\section{Conclusão}

A câmera digital multiespectral discrimina alterações espectrais do dossel da Urochloa brizantha cv. Marandu em função da adubação nitrogenada, e as medidas de NDVI obtidas se correlacionam com as características produtivas da gramínea

\section{Agradecimentos}

Os autores agradecem ao Instituto Federal de Educação Ciência e Tecnologia do Tocantins pelo apoio à pesquisa (edital $n^{\circ}$ 39/2014/Reitoria/IFTO) e ao CNPq pela concessão de bolsas de iniciação científica na modalidade PIBIC-EM.

\section{Referências}

Abrahão SA, Pinto FAC, Queiroz DM, Santos NT, Gleriani JM, Alves EA. Índices de vegetação de base espectral para discriminar doses de nitrogênio em capim-tanzânia. R Bras Zootec. 2009;38(9):1637-44.

Costa C, Dwyer LM, Dutilleul P, Stewart DW, Ma BL, Smith DL. Inter-relationships of applied nitrogen, SPAD, and yield of leafy and non-leafy maize genotypes. J Plant Nutr. 2001;8(24):1173-94.

Dworak V, Selbeck J, Dammer KH, Hoffmann M, Zarezadeh AA, Bobda C. Strategy for the Development of a Smart NDVI Camera System for Outdoor Plant Detection and Agricultural Embedded Systems. Sensors (Basel). 2013;13(2):1523-38.

Martha Jr GB, Vilela L, Sousa DMG, et al. Cerrado: Uso eficiente de corretivos e fertilizantes em pastagens. Planaltina, DF: Embrapa Cerrados; 2007. p.117-44.

Ministério da Agricultura, Pecuária e Abastecimento (MAPA). Pecuária brasileira reduz área e dobra produção em 36 anos [acesso 21 jan 2019]. Disponível em: https:// tinyurl.com/y47d6p4a
Read JJ, Whaley EL, Tarpley L, Reddy KR. Evaluation of a hand-held radiometer for field determination of nitrogen status in cotton. Digital Imaging and Spectral Techniques: Applications to Precision Agriculture and Crop Physiology. ASA Spec. Publ. 66. Madison, WI: ASA, CSSA, and SSSA; 2003. p. 177-95.

Roberts JJ, Trotter M, Lamb D, Hinch G, Schneider D. Spatio-temporal movement of livestock in relation to decreasing pasture biomass. Food Security from Sustainable Agriculture: Proceedings of the 15th Australian Agronomy Conference; 15-18 nov 2010; Lincoln, Nova Zelândia. Armidale, Australia: University of New England; 2010.

Silva Jr MC, Pinto FAC, Fonseca DM, Queiroz DM, Maciel BF. Detecção do efeito da adubação nitrogenada em Brachiaria decumbens Stapf. utilizando um sistema de sensoriamento remoto. R Bras Zootec. 2008;37(3):411-9. 